\title{
The Prevalence of Norovirus in returning international travelers with diarrhea
}

\author{
Nadja Apelt*1 ${ }^{* 1}$ Christine Hartberger ${ }^{2}$, Hartmut Campe ${ }^{2}$ and Thomas Löscher ${ }^{1}$
}

\begin{abstract}
Background: There is a high incidence of diarrhea in traveling populations. Norovirus (NV) infection is a common cause of diarrhea and is associated with $7 \%$ of all diarrhea related deaths in the US. However, data on the overall prevalence of NV infection in traveling populations is limited. Furthermore, the prevalence of NV amongst travelers returning to Europe has not been reported. This study determined the prevalence of NV among international travelers returning to Germany from over 50 destinations in and outside Europe.

Methods: Stool samples of a total of 104 patients with a recent ( $<14$ days) history of international travel (55 male, mean age $37 \mathrm{yrs}$.) were tested for the presence of NV genogroup (GG) I and II infection using a sensitive and well established quantitative RT PCR method. 57 patients experienced diarrhea at the time of presentation at the Department of Infectious Diseases \& Tropical Medicine. The remaining 47 patients had no experience of diarrhea or other gastrointestinal symptoms for at least 14 days prior to their date of presentation at our institute.

Results: In our cohort, NV infection was detected in $15.7 \%$ of returning travelers with diarrhea. The closer to the date of return symptoms appeared, the higher the incidence of NV, ranging as high as $21.2 \%$ within the first four days after return.

Conclusions: In our cohort, NV infection was shown to be frequent among returning travelers especially in those with diarrhea, with over $1 / 5$ of diarrhea patients tested positive for NV within the first four days after their return to Germany. Due to this prevalence, routine testing for NV infection and hygienic precautions may be warranted in this group. This is especially applicable to patients at an increased risk of spreading the disease, such as healthcare workers, teachers or food-handlers.
\end{abstract}

\section{Background}

An increased incidence of diarrhea can be detected in traveling populations [1]. In industrialized countries noroviruses (NV) are presently recognized as the most common cause of diarrhea in the adult population, both for epidemic [2] and sporadic [3] cases of diarrhea. It is estimated that they cause up to $85 \%$ of all viral enteritis worldwide [4]. Despite the high rate of recovery generally associated with NV infection, up to $7 \%$ of all diarrhearelated deaths in the US are thought to be caused by NV [5]. Thus, NV enteritis can be expected to cause signifi-

*Correspondence: ink_2010@hotmail.com

1 Department of Infectious Diseases and Tropical Medicine, LudwigMaximilians University of Munich, Georgenstr. 5, 80799 Munich, Germany

Full list of author information is available at the end of the article cant human and economic loss [6,7] which could be exacerbated in patients suffering co-morbid conditions.

Judging by two studies carried out in 2002 and in 2008 the economic and human impact that NV spread by travelers has on European public health systems appears to be substantial[8,9]. As with any rapidly mutating viral agent where pandemics due to newly emerging genotypes are reported nearly every two years, travelers are expected to significantly contribute to the spread of NV. A number of infected pilgrims returning from Lourdes was shown to cause more than 380 secondary cases including one fatality in 29 Swiss nursery homes [8]. In addition, 130 secondary cases, nine outbreaks and four deaths across France, the Netherlands and Ireland were directly attributable to epidemic enteritis spread by returning pilgrims from Lourdes [9]. 
RT-PCR methods have been recognized as the gold standard of NV detection [10-12]. A report of 35 patients with diarrhea that traveled from the US to Mexico in 2005 showed the exceptionally high rate of NV infection of $65 \%$ using a sensitive RT-PCR method [13]. In contrast, previous studies reported infection rates of only 5$15 \%$ in travelers suffering diarrhea in the 1980's using radioimmunoassay methods [14-16]. In spite of the discrepancies in the prevalence of $\mathrm{NV}$ infection reported amongst travelers, the data suggests that travelers are a particular group that is susceptible to NV infection. This warrants further investigation, especially since, to the best of our knowledge, no data has been published assessing the prevalence of $\mathrm{NV}$ amongst European traveling populations. By providing data on the scale of the problem at hand, the study of prevalence rates of NV infection among international travelers returning to Europe will significantly contribute to assessing the impact NV infected travelers have on European public health systems.

\section{Methods}

Fresh stool samples from 104 recently (< 14days) returned travelers with and without diarrhea were collected from August 2006 through May 2008 at the Department of Infectious Diseases and Tropical Medicine in Munich, Germany.

Sample preservation was performed as previously reported for NV preservation from stool [17-21], creating a $20 \%$ suspension of the sample in nuclease-free water and storing samples at $-80^{\circ} \mathrm{C}$ until testing. RNA extraction was carried out on the same day of RT-PCR testing. In short, the stool suspension was diluted to $10 \%$ using nuclease-free water and centrifuged at $3500 \mathrm{~g}$ for $10 \mathrm{~min}$ utes. RNA extraction was carried out using the „MicrolabStar" robot by Hamilton (Bonaduz, Switzerland) and the QiAmp biorobot kit by Qiagen (Hilden, Germany), following the manufacturers manual.

Samples were tested for NV genogroups I and II following a standard qRT-PCR protocol at the 'State Department for Health and Food Safety' as previously published [18]. Qiagen One Step RT-PCR kit was used, following the manufacturers protocols. Primers were synthesized by MWG Biotech (Ebersberg, Germany). Primers NV 192, NV 193 and probe TM8 were used for the detection of genogroup (GG) I viruses and primers 107a, NV 117 (corresponding to NV 119 in [18]) and probe TM3 for the detection of GGII (tab. 1). Reference dye of the reaction was "ROX" (Invitrogen, Karlsruhe, Germany).

Ethical clearance for the study was sought through the Ethical Committee of the Medical Faculty at LudwigMaximilians University, Munich, Germany. Clinical and laboratory data was used only in the case that patients had provided written informed consent to participate in this study or after written informed consent was obtained from the legal caretakers in the case of minors.

Statistical evaluation was carried out using SPSS 13.0 for Windows "student version" as well as standard applications of Microsoft Excel Version 2003.

\section{Results}

Of the 104 patients included in this study 55 were male. Sex was evenly distributed between patients with and without diarrhea ( $p=0.652$; chi-square test). The study included patients from 4 to 80 years of age (mean $37.8 \pm$ $14.7 \mathrm{yrs}$ ) without significant differences between patients with and without diarrhea $(\mathrm{p}=0.473$; one-way Anova test). The mean duration of the journey was comparable in patients with and without diarrhea ( $\mathrm{p}=0.949$ one-way Anova test) with 69 and 71 days, respectively. (tab. 2)

Overall 10 cases of NV infection were detected in this study, nine of which were found in patients with diarrhea (15.7\%), and one in the group of patients without diarrhea (2.1\%). Of the 10 cases of NV detected, eight were caused by GGII viruses alone, one was a coinfection with GGI and GGII and one case was an infection caused by GGI alone. As expected, the difference in the number of NV infections proved significant when comparing patients with and without diarrhea ( $\mathrm{p}=0.019$ by chi-square test). Both sexes were equally likely to be infected $(\mathrm{p}=0.210$, chi-square test). (tab. 2)

Of the nine positively tested patients that suffered diarrhea the following symptoms in addition to diarrhea were reported to the observing physician: fever (2), abdominal cramping (2), nausea (4), vomiting (2), headache (2) and myalgia (2).

Patients in this study visited a total of over 50 destinations. Traveling modality was shown to influence the odds of infection. All patients with diarrhea and 20 patients without diarrhea provided information as to their traveling modalities. Overall, 28 patients (36\%) had taken part in a back-packing/adventure trip, 19 (25\%) had participated in a packaged holiday, $13(17 \%)$ had been on a business trip and eight (10\%) were visiting friends and family. All other patients that gave information as to their way of traveling had either traveled as missionaries or exchange students. Comparing traveling modalities within the group of recently returned travelers with diarrhea, the backpacking trip was associated with the highest risk of a positive NV test result, when compared to other forms of traveling $(\mathrm{OR}=4.923)$. The business trip carried the second highest risk of infection $(\mathrm{OR}=1.429)$, and those who had traveled on a packaged holiday carried the lowest risk of a positive test result $(\mathrm{OR}=0.304)$. (tab. 2) 
Table 1: Primer sequences. Primer sequences used for the detection of norovirus. Primers for both genotypes target the ORF1/ORF2 overlap of the viral genome.

\begin{tabular}{llll}
\hline Genogroup & Primer & Sequence & Location* $^{*}$ \\
\hline G I & NV 192 & 5'- gC (CT) Atg TTC CgC Tgg Atg C - 3' & $5282-5300$ \\
G I & NV 193 & 5'- CgT CCT Tag ACg CCA TCA TCA - 3' & $5379-5359$ \\
G I & TM8 & 5'- FAM - Tgg ACA gg(Ag) gAT CgC (Ag)AT & $5321-5345$ \\
& Probe & CTC CTg C - 3' - TMR & $5007-5026$ \\
G II & NV 107a & 5'- AgC CAA TgT TCA gAT ggA Tg - 3' & $5100-5081$ \\
G II & NV 117 & 5'- TCg Acg CCA TCT TCA TTC AC-3' & $5048-5070$ \\
G II & TM3 & 5'- FAM - Tgg gAg ggC gAT CgC AAT CTg gC - & \\
\hline
\end{tabular}

${ }^{*}$ Genome location of primers and probes are based for Gl on the sequence of Norwalk/68/US [GenBank: M87661] and for Gll on the sequence of Lordsdale/93/UK [GenBank: $\underline{\text { 866557]; }}$

It took patients with diarrhea $4.7 \pm 3.0$ days (minimum 0 , maximum 13; $95 \%$ confidence interval 3.92-5.52 days) and patients without diarrhea $5.3 \pm 3.5$ days (min. 0 , max. 14; $95 \%$ confidence interval $4.32-6.36$ days) to present at our clinic for the first time after returning to Germany. These time spans are comparable for both groups $(\mathrm{p}=$ 0.330 One-way Anova test). (tab. 2) Eight of the nine positively tested patients with diarrhea had visited the clinic within the first five days after their return. Five of nine diarrhea patients which were tested positive claimed to have suffered from diarrhea since before their return to Germany, the remaining four declared to have started experiencing symptoms within the first four days after their return. (Fig. 1) 21.2\% of diarrhea patients tested for
NV within the first four days after their return to Germany tested positive. There was no significant correlation between the duration of the journey and the likelihood of $\mathrm{NV}$ infection.

\section{Discussion}

NV enteritis is generally recognized as an acute self-limiting disease inducing vomiting and watery non-bloody diarrhea lasting 12 to 60 hours. Recovery is usually complete and complications are rare in the non-comorbid adult population [12,22-25]. However, it has been shown that infants, elderly and immunocompromised patients, and those suffering cardiovascular disease are significantly more likely to experience a complicated or fatal

Table 2: Overview of results. Demographic data and frequency of norovirus (NV) infection in recently returned travelers with diarrhea and in a control group of recently returned travelers without diarrhea:

\begin{tabular}{|c|c|c|c|}
\hline & $\begin{array}{l}\text { Patients with diarrhea } \\
\qquad(n=57)\end{array}$ & $\begin{array}{l}\text { Asymptomatic patients } \\
\qquad(n=47)\end{array}$ & $\begin{array}{l}\text { Differences } \\
\text { between groups }\end{array}$ \\
\hline Male & 29 & 26 & $p=0.652$ \\
\hline Mean age (yrs) & $38.7 \pm 15.7$ & $36.6 \pm 13.4$ & $p=0.437$ \\
\hline Mean duration of journey (days) & $68.5 \pm 166$ & $71.2 \pm 266$ & $p=0.949$ \\
\hline NV infection & $9(15.7 \%)$ & $1(2.1 \%)$ & $p=0.019$ \\
\hline GGI & 1 & 0 & \\
\hline GGII & 7 & 1 & \\
\hline GGI + GGII coinfection & 1 & 0 & \\
\hline $\begin{array}{l}\text { Traveling modality and corresponding } \\
\text { odds of infection }\end{array}$ & $\begin{array}{l}\text { Backpacking trip: } \mathrm{OR}=4.923 \\
\text { Business trip: } \mathrm{OR}=1.429 \\
\text { Packaged holiday: } \mathrm{OR}=0.304\end{array}$ & & \\
\hline $\begin{array}{l}\text { Time until presentation at clinic after } \\
\text { return (in days) }\end{array}$ & $4.7 \pm 3.0$ & $5.3 \pm 3.5$ & $p=0.330$ \\
\hline India (total/NV+) & $13 / 4$ & $8 / 1$ & \\
\hline Backpacker (total/NV+) & $22 / 6$ & $6 / 0$ & \\
\hline
\end{tabular}




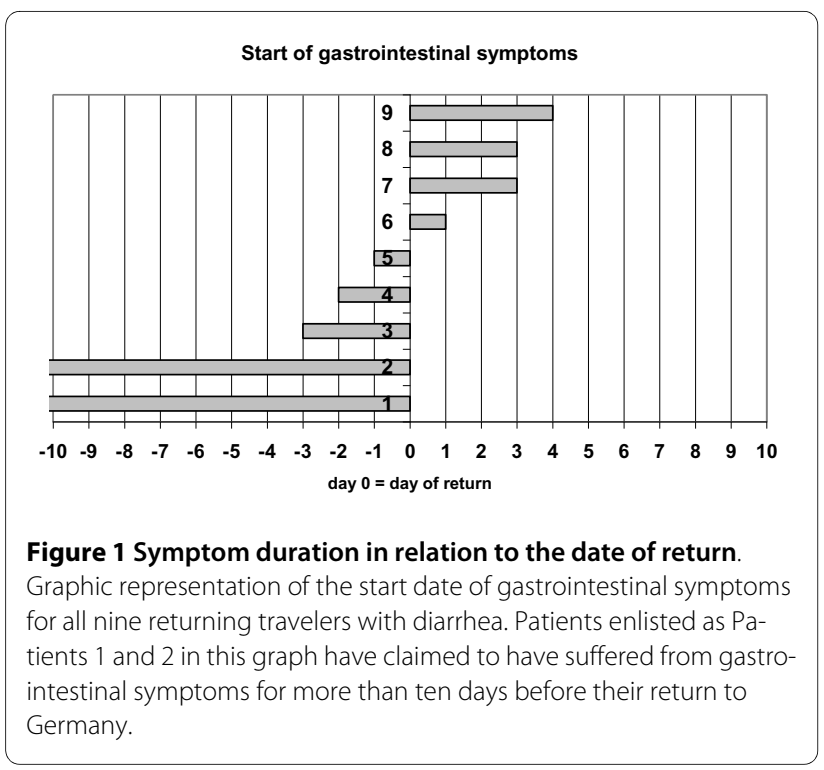

course $[12,26]$. The most common consequence of the disease is dehydration, even though secondary complications as diverse as aspiration pneumonia, renal failure, mucositis and acute abdomen have been described $[12,26]$.

Pandemics caused by newly emerged genotypes of NV, in particular genotype GII.4, have been reported approximately every two years since 2002 [27]. This is thought to be due to the high mutation potential of NV. Indeed the mutation rate of NV has been quoted to be significantly higher than that of influenza viruses [28]. The present study shows a high rate of $\mathrm{NV}$ infection in travelers returning to Germany suffering diarrhea. Overall, 15.7\% of diarrhea patients were infected with the virus. As a comparison, only four in 79 travelers (2\%) returning from the US to Sweden with respiratory symptoms were shown to suffer from influenza type A (H1N1) in a recent survey [29].

Our results support previous findings of a high prevalence of NV among US travelers for the first time in a European population and compare to findings quoted in a recent review [30]. Furthermore we show that in this population, the closer to the date of return diarrhea developed, the higher the rate of NV+ cases, reaching $21 \%$ for patients suffering diarrhea within four days after their return.

NV is a common cause of diarrhea in the adult population. Thus, when evaluating the frequency of NV in a traveling population it should always be kept in mind that $\mathrm{NV}$ may be equally prevalent in a non-traveling population. In an unpublished in-house study at the Department of Infectious Diseases and Tropical Medicine the prevalence of NV unrelated to travel was assessed in 48 diarrhea patients using the method described in this paper (personal communication). As the largest part of patients at our clinic possesses a clinical history of recent travel, a cut-off point was established to define patients whose symptomatic NV infection was unlikely to be linked to travel. This cut-off point was chosen at 14 days after return from the last international journey and NV infections in patients that presented to the clinic 14 days or more after their return were considered to be unrelated to travel. This choice was based on the maximum incubation time reported for $\mathrm{NV}$ that was estimated at 130 hours [31] and the mean duration of symptoms for the common GII.4 virus group that was reported to average 69 hours [32]. In this group of 48 diarrhea patients a single patient has been found to suffer NV infection (2.1\%). The low prevalence in this cohort may indicate that traveling might be an independent risk factor for the contraction of NV.

It was a special interest of ours to identify those diarrhea patients at highest risk for NV among the inhomogeneous group of returning travelers. The Department of Infectious Diseases and Tropical Medicine routinely collects data on the mode of traveling of patients. Hence, we could observe participants in backpacking/adventure trips to be the most likely to have contracted NV infection when compared to other returning travelers with diarrhea $(\mathrm{OR}=4.923)$. Having traveled on a packaged holiday lowered the likelihood of $\mathrm{NV}$ when experiencing diarrhea $(\mathrm{OR}=0.304)$. We also consider it remarkable for $30.1 \%$ of returnees from India suffering diarrhea to have been tested $\mathrm{NV}+$, even though we are fully aware of the fact that the scale of this investigation does not allow any conclusions as to the likelihood with which NV affects visitors to specific destinations.

\section{Conclusion}

A prevalence of NV of $21.2 \%$ among diarrhea patients within the first four days after their return from an international journey may be sufficiently high to warrant routine testing for NV in this group. Recent studies suggest that $\mathrm{NV}$ is continuously shed for an average of 28 days after symptoms subside [31], even though detection techniques may oftentimes not be sensitive enough to detect viral shedding for more than 14 days after the end of symptoms. However, bearing in mind that $10-100$ viral particles are sufficient to induce symptomatic NV infection $[33,34]$ it is highly likely that patients remain infectious for all of the 28 days that virus may be shed. Thus routine NV testing in populations where NV is highly prevalent may serve as a measure of public health prevention. It allows doctors to take preventive action in the case of a positive test result, especially were persons at increased risk for spreading the disease such as health care workers, teachers and food handlers are concerned. 


\section{Competing interests}

The authors declare no existing conflict of interests. No third party funding has been used in the generation of the presented data.

\section{Authors' contributions}

All authors have read and approved of the final manuscript and have contributed to the presented work as follows. NA carried out the sample collection, sample testing, statistical analysis and drafted the manuscript. NA also participated in study design. $\mathrm{CH}$ carried out the sample testing while $\mathrm{HC}$ provided machines, reagents and facilities for sample testing. TL conceived of the study and participated in its design and coordination. TL also contributed to the drafting of the manuscript.

\section{Author Details}

'Department of Infectious Diseases and Tropical Medicine, Ludwig-

Maximilians University of Munich, Georgenstr. 5, 80799 Munich, Germany and

${ }^{2}$ State Department for Health and Food Safety - Landesamt für

Gesundheitsschutz und Lebensmittelsicherheit, Oberbayern, Veterinärstr. 2

Oberschleißheim, Germany

Received: 23 December 2009 Accepted: 25 May 2010

Published: 25 May 2010

\section{References}

1. Spira AM: Assessment of travellers who return home ill. Lancet 2003, 361(9367):1459-1469.

2. Glass RI, Noel J, Ando T, Fankhauser R, Belliot G, Mounts A, Parashar UD, Bresee JS, Monroe SS: The epidemiology of enteric caliciviruses from humans: a reassessment using new diagnostics. J Infect Dis 2000, 181(Suppl 2):S254-261.

3. Rockx B, De Wit M, Vennema H, Vinje J, De Bruin E, Van Duynhoven Y, Koopmans M: Natural history of human calicivirus infection: a prospective cohort study. Clin Infect Dis 2002, 35(3):246-253.

4. Lopman BA, Reacher MH, Van Duijnhoven Y, Hanon FX, Brown D, Koopmans M: Viral gastroenteritis outbreaks in Europe, 1995-2000. Emerg Infect Dis 2003, 9(1):90-96.

5. Mead PS, Slutsker L, Dietz V, McCaig LF, Bresee JS, Shapiro C, Griffin PM, Tauxe RV: Food-related illness and death in the United States. Emerg Infect Dis 1999, 5(5):607-625

6. Zingg W, Colombo C, Jucker T, Bossart W, Ruef C: Impact of an outbreak of norovirus infection on hospital resources. Infect Control Hosp Epidemiol 2005, 26(3):263-267.

7. Lopman BA, Reacher MH, Vipond IB, Hill D, Perry C, Halladay T, Brown DW, Edmunds WJ, Sarangi J: Epidemiology and cost of nosocomial gastroenteritis, Avon, England, 2002-2003. Emerg Infect Dis 2004, 10(10):1827-1834

8. Fretz R, Schmid H, Kayser U, Svoboda P, Tanner M, Baumgartner A: Rapid propagation of norovirus gastrointestinal illness through multiple nursing homes following a pilgrimage. Eur $J$ Clin Microbiol Infect Dis 2003, 22(10):625-627.

9. Verhoef L, Duizer E, Vennema H, Siebenga J, Swaan C, Isken L, Koopmans M, Balay K, Pothier P, McKeown P, Van Dijk G, Capdepon P, Delmas G: Import of norovirus infections in the Netherlands and Ireland following pilgrimages to Lourdes, 2008--preliminary report. Euro Surveill 2008, 13(44):pii. 19025

10. Jiang X, Wang J, Graham DY, Estes MK: Detection of Norwalk virus in stool by polymerase chain reaction. J Clin Microbio/ 1992, 30(10):2529-2534

11. De Leon R, Matsui SM, Baric RS, Herrmann JE, Blacklow NR, Greenberg HB, Sobsey MD: Detection of Norwalk virus in stool specimens by reverse transcriptase-polymerase chain reaction and nonradioactive oligoprobes. J Clin Microbiol 1992, 30(12):3151-3157.

12. Koch J, Schneider T, Stark K, Schreier E: Norovirusinfektionen in Deutschland. Bundesgesundheitsbl-GesundheitsforschGesundheitsschutz 2006, 49:296-309.

13. Chapin CMCAR, Dudley William C, Gibson Lucy C, Rafael Pratdesaba, Olga Torres, Domingo Sanchez, Jaime Belkind-Gerson, Irene Nyquist, Anders Kärnell, Bjorn Gustafsson, Halpern Jane L, Bourgeois Louis A, Schwab Kellogg J: Prevalence of Norovirus among Visitors from the United
States to Mexico and Guatemala Who Experience Traveler's Diarrhea. Journal of Clinical Microbiology 2005, 43(3):1112-1117.

14. Keswick BH, Blacklow NR, Cukor GC, DuPont HL, Vollet JL: Norwalk virus and rotavirus in travellers' diarrhoea in Mexico. Lancet 1982, 1(8263):109-110.

15. Ryder RW, Oquist CA, Greenberg H, Taylor DN, Orskov F, Orskov I, Kapikian AZ, Sack RB: Travelers' diarrhea in panamanian tourists in Mexico. J Infect Dis 1981, 144(5):442-448

16. Taylor DN, Echeverria P, Blaser MJ, Pitarangsi C, Blacklow N, Cross J, Weniger BG: Polymicrobial aetiology of travellers' diarrhoea. Lancet 1985, 1(8425):381-383.

17. Rowena A, Bull ETVT, Mclver Christopher J, Rawlinson William D, White Peter A: Emergence of a New Norovirus Genotype II.4 Variant Associated with Global Outbreaks of Gastroenteritis. Journal of Clinical Microbiology 2006, 44(2):327-333.

18. Hoehne Marina ES: Detection of Norovirus genogroup I and II by multiplex real-time RT- PCR using a 3'-minor groove binder-DNA probe. BMC Infectious Diseases 2006, 69(6):

19. Anthony C, Ike SOB, Kathrin Hartelt, Marschang Rachel E, Matthias Contzen, Oehme Rainer M: Molecular Epidemiology of Norovirus in Outbreaks of Gastroenteritis in Southwest Germany from 2001 to 2004. Journal of Clinical Microbiology 2006, 44(4):1262-1267.

20. Schmid Michael RO, Gunnar Schalasta, Stefan Brockmann, Peter Kimmig, Gisela Enders: Fast detection of Noroviruses using a real-time PCR assay and automated sample preparation. BMC Infectious Diseases 2004, 15(4):.

21. Gary P, Richards MAW, Fankhauser Rebecca L, Monroe Stephan S: Genogroup I and II Noroviruses Detected in Stool Samples by RealTime Reverse Transcription-PCR Using Highly Degenerate Universal Primers. Applied and Environmental Microbiology 2004, 70(12):7179-7184.

22. CDC: "Norwalklike viruses": public health consequences and outbreak management. Morbidity and Mortality Weekly Report 2001, 50(9):1-18.

23. Sasaki Y, Kai A, Hayashi Y, Shinkai T, Noguchi Y, Hasegawa M, Sadamasu K, Mori K, Tabei Y, Nagashima M, Morozumi S, Yamamoto T: Multiple Viral Infections and Genomic Divergence among Noroviruses during an Outbreak of Acute Gastroenteritis. Journal of Clinical Microbiology 2006, 44(3):790-797.

24. Hutson AM, Atmar RL, Estes MK: Norovirus disease: changing epidemiology and host susceptibility factors. Trends Microbiol 2004, 12(6):279-287

25. Papadopoulos VP, Vlachos O, Isidoridou E, Kasmeridis C, Pappa Z, Goutzouvelidis A, Filippou F: A Gastroenteritis Outbreak due to Norovirus Infection in Xanthi, Northern Greece: Management and Public Health Consequences. Journal of Gastrointestinal and Liver Diseases 2006, 15(1):27-30.

26. Mattner F, Sohr D, Heim A, Gastmeier P, Vennema H, Koopmans M: Risk groups for clinical complications of norovirus infections: an outbreak investigation. Clinical Microbiology and Infection 2006, 12:69-74.

27. Kroneman $A$, Verhoef $L$, Harris J, Vennema $H$, Duizer $E$, van Duynhoven $Y$, Gray J, Iturriza M, Bottiger B, Falkenhorst G, Johnsen C, von Bonsdorff CH, Maunula L, Kuusi M, Pothier P, Gallay A, Schreier E, Höhne M, Koch J, Szücs G, Reuter G, Krisztalovics K, Lynch M, McKeown P, Foley B, Coughlan S, Ruggeri FM, Di Bartolo I, Vainio K, Isakbaeva E, et al: Analysis of integrated virological and epidemiological reports of norovirus outbreaks collected within the foodborne viruses in Europe Network from 1 July 2001 to 30 June 2006. J Clin Microbiol 2008, 46(9):2959-2965.

28. Smith DJ, Lapedes AS, de Jong JC, Bestebroer TM, Rimmelzwaan GF, Osterhaus AD, Fouchier RA: Mapping the antigenic and genetic evolution of influenza virus. Science 2004, 305(5682):371-376.

29. Follin P, Lindqvist A, Nystrom K, Lindh M: A variety of respiratory viruses found in symptomatic travellers returning from countries with ongoing spread of the new influenza $\mathrm{A}(\mathrm{H} 1 \mathrm{~N} 1) \mathrm{v}$ virus strain. Euro Surveill 2009, 14(24):

30. DuPont $\mathrm{HL}$ : Systematic review: the epidemiology and clinical features of travellers' diarrhoea. Aliment Pharmacol Ther 2009, 30(3):187-196.

31. Atmar RL, Opekun AR, Gilger MA, Estes MK, Crawford SE, Neill FH, Graham DY: Norwalk virus shedding after experimental human infection. Emerg Infect Dis 2008, 14(10):1553-1557. 
32. Jansen A, Beyer A, Brandt C, Hohne M, Schreier E, Schulzke J, Zeitz M, Schneider T: The norovirus-epidemic in Berlin - clinic, epidemiology, and prevention. Z Gastroenterol 2004, 42(4):311-316.

33. Iversen AM, Gill M, Bartlett CL, Cubitt WD, MCSwiggan DA: Two outbreaks of foodborne gastroenteritis caused by a small round structured virus: evidence of prolonged infectivity in a food handler. Lancet 1987, 2(8558):556-558.

34. Jaykus $L$ : Detection of human enteric viruses in foods. In Foodborne Disease Handbook; Viruses, Parasites, and HACCP 2nd edition. New York, NY: Marcel Dekker, Inc; 2000

\section{Pre-publication history}

The pre-publication history for this paper can be accessed here: http://www.biomedcentral.com/1471-2334/10/131/prepub

doi: $10.1186 / 1471-2334-10-131$

Cite this article as: Apelt et al., The Prevalence of Norovirus in returning international travelers with diarrhea BMC Infectious Diseases 2010, 10:131

Submit your next manuscript to BioMed Central and take full advantage of:

- Convenient online submission

- Thorough peer review

- No space constraints or color figure charges

- Immediate publication on acceptance

- Inclusion in PubMed, CAS, Scopus and Google Scholar

- Research which is freely available for redistribution

Submit your manuscript at www.biomedcentral.com/submit
C) Biomed Central 